\title{
Extracutaneous involvement of pyoderma gangrenosum
}

\author{
Luis J. Borda ${ }^{1}$. Lulu L. Wong ${ }^{1}$ - Angelo V. Marzano ${ }^{2} \cdot$ Alex G. Ortega-Loayza $^{3}$
}

Received: 24 August 2018 / Revised: 31 December 2018 / Accepted: 21 March 2019 / Published online: 29 March 2019

(c) Springer-Verlag GmbH Germany, part of Springer Nature 2019

\begin{abstract}
Pyoderma Gangrenosum (PG) is an inflammatory neutrophilic dermatosis (ND) associated with underlying chronic inflammation and/or malignancy. Diagnosis remains to be challenging as a gold standard diagnostic test is lacking. Initial manifestations may include papules, vesicles, or pustules that subsequently develop into ulceration with features of undermining and violaceous borders. Timely recognition of pyoderma gangrenosum is impeded by clinical findings shared with other etiologies, such as granulomatosis with polyangiitis, polyarteritis nodosa, and antiphospholipid syndrome. As with any other ND, extracutaneous involvement may also occur preceding, during, or following the appearance of skin lesions. Sterile neutrophilic infiltrates have been found to affect internal organs supporting the concept of PG being a systemic disease, with lung being the most common extracutaneous manifestation followed by ocular and visceral compromise. Therefore, in this review, we describe the current knowledge of extracutaneous involvement of PG and its respective clinical manifestations to aid dermatologists in diagnosis, management, and determining prognosis.
\end{abstract}

Keywords Pyoderma gangrenosum $\cdot$ Extracutaneous $\cdot$ Neutrophilic dermatosis $\cdot$ Pulmonary $\cdot$ Ocular $\cdot$ Renal $\cdot$ Bone

\section{Introduction}

Pyoderma Gangrenosum (PG) is considered an inflammatory neutrophilic dermatosis (ND) often associated with underlying chronic inflammation and neoplastic disease [13]. The pathophysiology of this rare skin condition is not completely understood; however, neutrophilic dysfunction, immune dysregulation, and genetic variations have been proposed as main contributors to PG pathogenesis [5]. The annual world-wide incidence is estimated to be 3-10 cases per million population, affecting all genders and age groups with peak incidence between age 20 and 50 years $[5,46]$.

Alex G. Ortega-Loayza

ortegalo@ohsu.edu

1 Department of Dermatology and Cutaneous Surgery, University of Miami Miller School of Medicine, Miami, FL, USA

2 UOC Dermatologia, IRCCS Fondazione Ca' Granda Ospedale Maggiore Policlinico, Dipartimento di Fisiopatologia Medico-Chirurgica e dei Trapianti, Università degli Studi di Milano, Milan, Italy

3 Department of Dermatology and OHSU Wound and Hyperbaric Medicine, Oregon Health and Science University, 3303 SW Bond Ave Center for Health and Healing Building 1, Suite 16, Portland, OR 97239, USA
Different variants of PG exist, such as ulcerative, bullous, pustular, vegetative, peristomal, and post-surgical [2]. Although a panel of experts recently proposed diagnostic criteria of ulcerative PG [42], a gold standard diagnostic test is still lacking. Initial clinical findings might include papules, vesicles, or pustules that develop into an ulcer featured by undermining, violaceous/necrotic borders, and excruciating pain. These lesions may be associated with preceding trauma (i.e., pathergy), malignancies, or inflammatory conditions such as rheumatoid arthritis and inflammatory bowel disease [5]. In addition, pyoderma-like ulcers have been described in other entities associated with systemic manifestations, such as granulomatosis with polyangitis (GPA) [24, 40], polyarteritis nodosa (PAN) [8, 23], and antiphospholipid syndrome (APL) [23, 56] (Table 1).

PG is the prototype of NDs, and with any other ND, noncutaneous involvement may occur before, during, or after the skin lesions [61]. In general, these non-cutaneous findings are categorized into three subtypes: (1) systemic inflammation common to other diseases associated with ND, such as gastrointestinal, hematologic, and rheumatologic conditions [39]; (2) non-specific inflammatory findings such as myalgia, fever, and joint pain; (3) sterile neutrophilic infiltrates found in organs other than skin [39]. The latter has been of special interest in patients with PG, as visceral involvement 


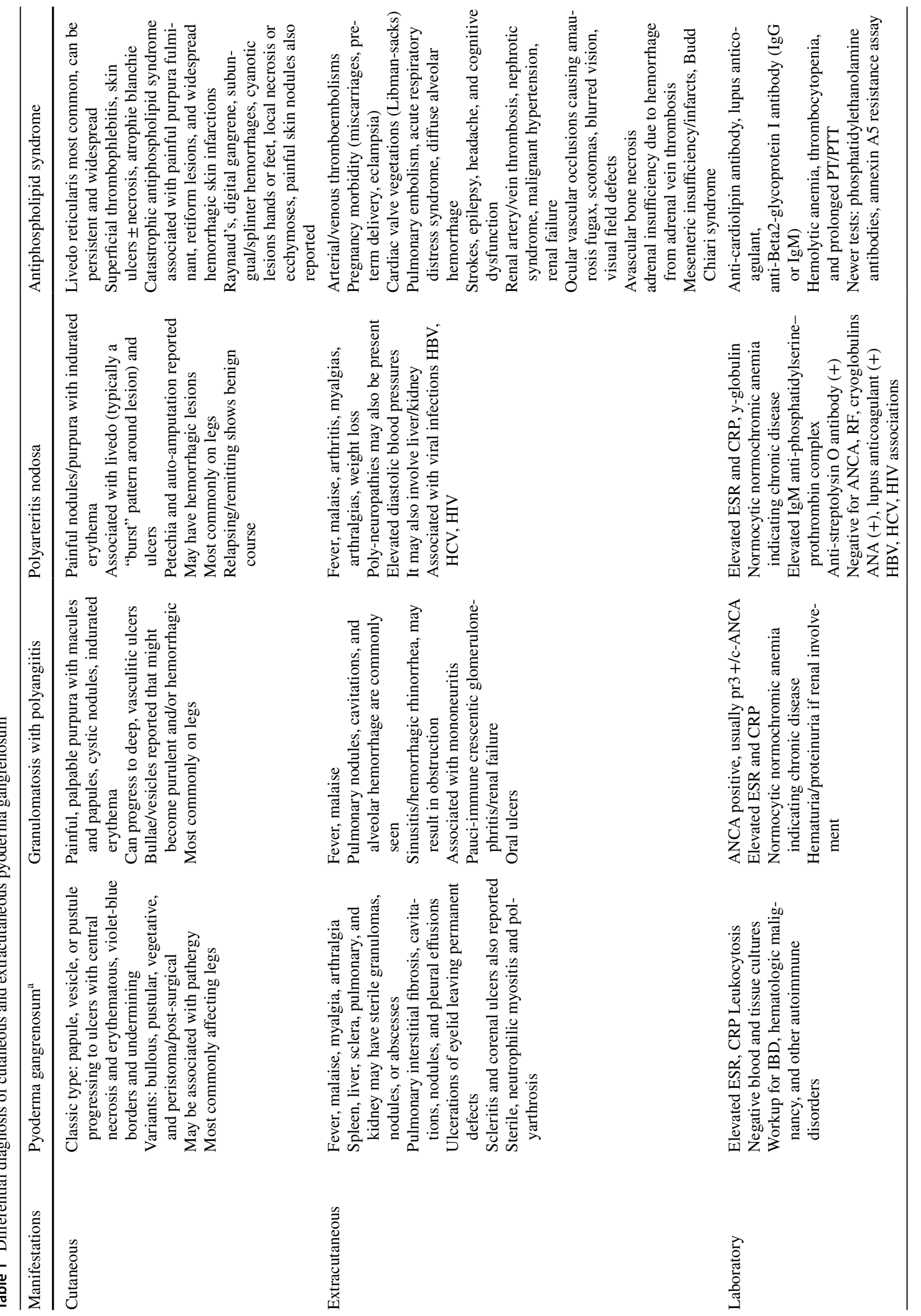




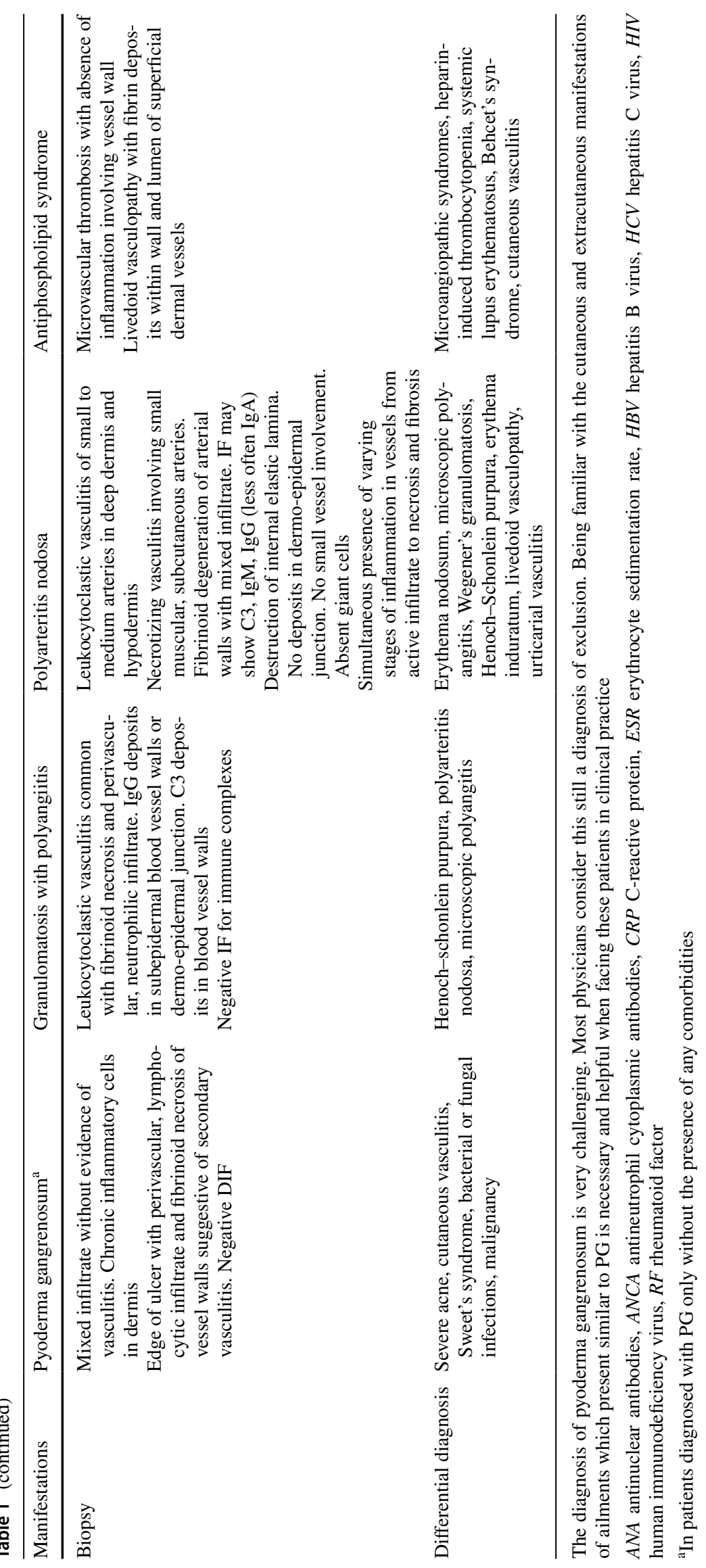


supports the idea of PG being a systemic disease [41, 61, 62]. Among the systemic manifestations of PG, pulmonary involvement is the most common, followed by ocular and other visceral involvements [27, 51]. Thus, the focus of this review is to describe extracutaneous manifestations of PG as these could aid in the diagnosis, management and prognosis of PG patients.

\section{Methods}

A search for all reported instances of extracutaneous PG was conducted using 12 key terms (pulmonary, lung, renal, kidney, ocular, eye, brain, gastrointestinal, heart, muscle, spleen, and extracutaneous) in combination with the search phrase "pyoderma gangrenosum" within the databases PubMed and Web of Science. All relevant English articles published between 1973 and 2018 were reviewed by two independent researchers. When the data were unclear, the senior author was asked to clarify the data extraction. Ninety-six cases were identified with extracutaneous manifestations of PG. Forty-one cases were reported as pulmonary involvement (41/96, 42.7\%), 34 as ocular involvement (34/96, 35.4\%), 7 as bone involvement (7/96, 7.2\%), 6 as spleen compromise $(6 / 96,6.2 \%)$, and 3 as renal involvement (3/96, 3.1\%). Less commonly involved organs, including brain, gastrointestinal, muscle, and heart compromise, were reported in 5 cases $(5 / 96,5.2 \%)$.

\section{Extracutaneous manifestations of PG}

\section{PG and pulmonary involvement}

The most common manifestation of extracutaneous PG is pulmonary involvement $[22,28,38,55]$. If present, $\mathrm{PG}$ with pulmonary involvement may result in life-threatening consequences and requires prompt recognition and treatment [55]. Pulmonary disease in patients with PG has a wide clinical presentation, ranging from asymptomatic to severe respiratory distress [22] (Fig. 1). Most cases involve cavitating or non-cavitating lesions that can be associated with necrosis and superimposed infections [38]. Interstitial infiltrates, consolidation or mediastinal lymphadenopathy can also occur $[38,55]$. PG with pulmonary involvement must be thoroughly evaluated for other etiologies and is a diagnosis of exclusion. Evaluation for mycobacterial and fungal infection, systemic vasculitides, and malignancies may be relevant to exclude other causes for pulmonary lesions besides PG lung involvement $[38,55]$.

Accurate diagnosis is often delayed as common etiologies such as cancer, infection, and necrotizing vasculitis can have similar presentations [22]. Though superimposed infections may further complicate diagnosis, negative tuberculosis and fungal testing can further support PG diagnosis in the presence of cavitating or necrotic lesions [55]. Due to the rarity of pulmonary PG and its variability in clinical course, there are still no clinical guidelines for when and how to test PG patients for pulmonary involvement. Hence, a diagnostic algorithm has been developed in a recent systematic review [28]. Lung disease in PG can also be mistaken for GPA, as lung infiltrates, nodules, and cavitation are also common findings for GPA [14, 48, 59, 60]. Similar to PG, GPA may present with a wide range of clinical symptoms, ranging from asymptomatic to severe respiratory distress [14]. Unlike PG, approximately $85 \%$ of patients with GPA will develop lung disease, and pulmonary involvement is considered a diagnostic criteria for the disease [59]. Many cases of pulmonary GPA are also associated with underlying systemic involvement [48]. However, those who have localized disease of GPA in the lungs have a relatively benign disease course [48]. Additionally, most cases of PG with pulmonary involvement initially present with skin ulcerations [28], though rare and questionable cases of lung involvement preceding skin disease have been reported [22]. PG patients with lung involvement are often idiopathic and mainly associated with hematologic malignancies [28]. Both pulmonary manifestations of PG and GPA can cause unilateral or bilateral lung disease; however, pulmonary involvement in patients with PG can affect all lung zones while GPA appears to spare the apices $[14,22]$. Pulmonary disease in PG can represent a challenge to distinguish from GPA strictly by clinical presentation, thus negative anti-neutrophil cytoplasmic antibody with cytoplasmic pattern (c-ANCA) testing (and other autoimmune work up), and biopsy can improve diagnostic confidence. Histopathology from lung tissue in patients with PG and pulmonary involvement usually reveals chronic inflammation with a predominance of neutrophils and an absence of vasculitis or malignant cells $[22,28,55]$.

The treatment of PG with pulmonary involvement is challenging and the disease can be fatal. Systemic corticosteroids and other immunosuppressants are most commonly used [28, 38], though corticosteroid resistance has been reported [55]. Patients being treated for pulmonary disease are immunosuppressed and carry a significant risk for lifethreatening infections $[22,28,55]$. Currently, there is a lack of long-term outcome studies in patients who suffer from PG with pulmonary involvement, but prognosis is generally favorable after treatment with no report of relapse [22].

\section{PG and ocular involvement}

Ocular manifestations in PG are rare, with only several case reports currently in the literature [19, 27, 45, 50] (Fig. 1). Early diagnosis of ocular PG is especially challenging, 


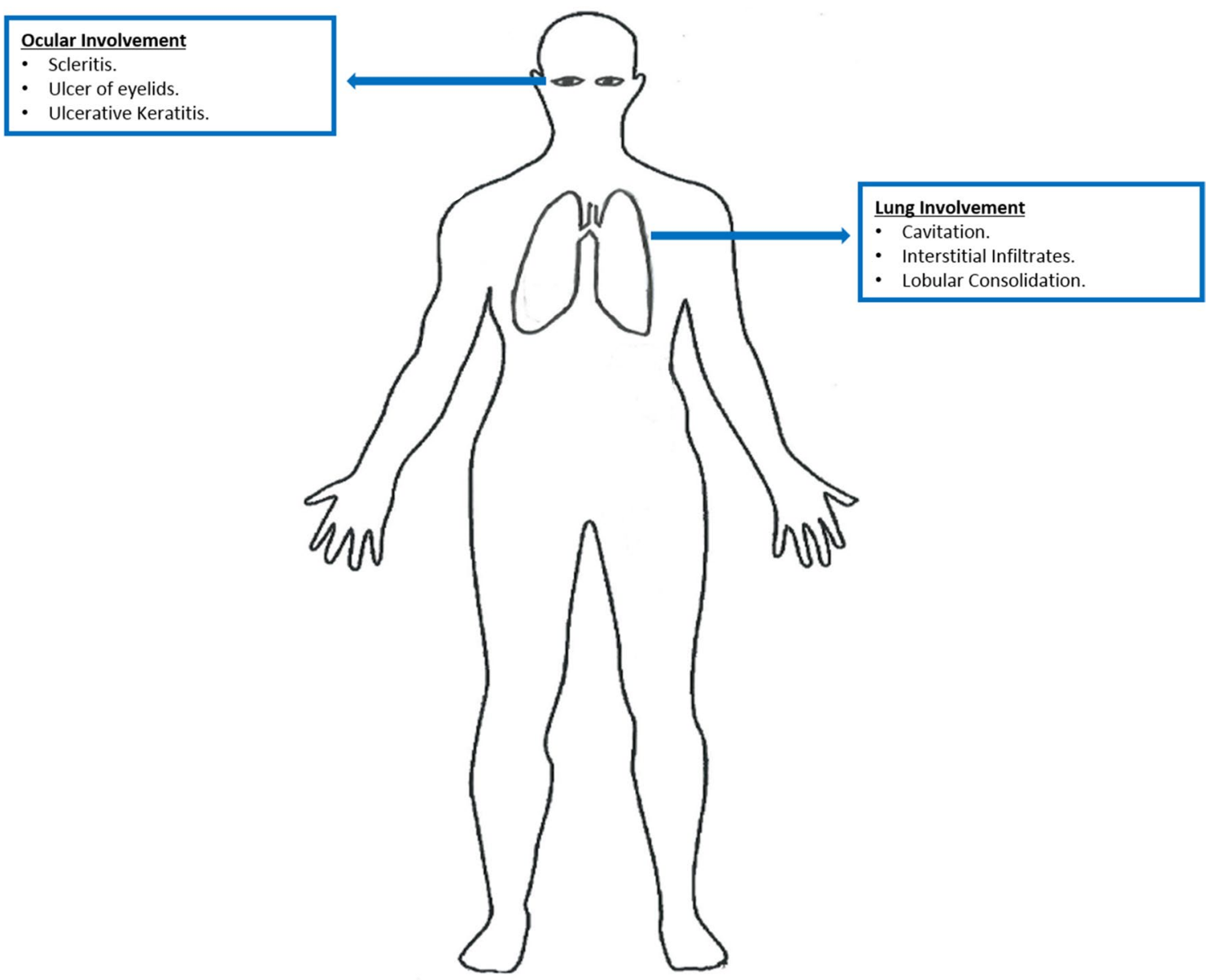

Fig. 1 Most common extracutaneous involvement in pyoderma gangrenosum

delaying initiation of appropriate treatment resulting in poor patient outcomes. Poor recognition of PG with ocular involvement is due to both the rarity and variability in its presentation.

There are several features of PG with ocular involvement that may aid the prompt diagnosis of this disease. PG with ocular involvement can affect the periorbital tissues and skin, usually presenting with eyelid swelling and nodules early on in the disease course [50]. Affected periorbital tissues may further progress to purulent discharge and necrosis of the affected tissues [27, 50]. A common manifestation is necrotic ulceration and fistula in the eyelids leading to defects in the eyelid itself, especially affecting the medial third upper lid and the lateral two-thirds of the lower lids [50]. Healing often takes months and recurrence is extremely common, with orbital involvement associated with a higher rate of relapse [27]. Orbital involvement can present with scleritis, proptosis, and conjunctival injection [19, 45, 50]. The difficulty establishing PG with ocular involvement is further convoluted by the fact that inflammatory bowel disease can experience ocular manifestations such as episcleritis and uveitis, mainly in association with concomitant musculoskeletal manifestations [27]. However, PG with eye involvement has been associated with IBD in only $15 \%$ of these cases and mainly affects the cutaneous tissues around the eye and the orbit [27].

Diagnosis of ocular PG is challenging, thus skin biopsy can be helpful, even though up to $40 \%$ of PG is associated with pathergy. Some cases of ocular involvement after minor trauma or surgical ophthalmic procedure have been reported [19]. However, the risk of delaying the treatment of PG, especially with eye involvement, greatly exceeds the concern for pathergy. Histology of ocular PG involves a sterile, inflammatory process with an acute or chronic infiltrate that may be associated with necrosis or dermal abscess [27, 45]. Though necrosis and fistulas of the periorbital tissues may be relatively non-specific and confuse the clinical picture to appear like GPA, the presence of painful eyelid nodules early on in the disease course is highly suggestive of PG rather than ocular GPA [50]. To further distinguish PG with eye involvement from GPA, absence of nasolacrimal obstruction and sinus disease makes GPA less likely [31, 59]. Frank, full-thickness necrosis in the eyelids, as seen in 
more advanced periorbital disease of PG, is also less characteristic of ocular GPA [27, 30, 31, 50, 59].

PG with eye involvement may lead to permanent damage to the orbit, resulting in vision loss. PG patients can suffer from corneal perforations leading to blindness, due to ulceration of the eyelids leading to full-thickness necrosis of the eyelids $[27,50]$. Orbital-cutaneous fistulas may also arise as a complication of untreated ocular PG [45], and other residual effects may involve loss of visual acuity, lagophthalmos, and defective eye motility [27].

\section{PG and renal involvement}

Renal involvement in PG has been rarely reported. It may present as pyuria, hematuria, aseptic leukocyturia, oliguria, and proteinuria as a result of different types of renal compromise $[9,10,39,57]$. Though few in number, several renal conditions have reportedly been associated with PG, such as chronic sclerosing glomerulonephritis, chronic kidney disease, end-stage renal disease (ESRD), renal carcinoma, and renal transplant, among others $[3,4,6,11,26,29,33$, 49, 53, 57] (Fig. 2).

Few cases have reported the association of PG with chronic kidney disease and end-stage renal disease (CKD/ ESRD); however, the underlying pathophysiology is yet to be elucidated [11, 26, 29,53]. Several theories have been proposed about the underlying mechanism of $\mathrm{PG}$ in patients with CKD/ESRD. Goto et al. proposed an underlying mechanism of hypersensitivity in a patient with CKD and uveitis associated with recurring PG lesions at injection sites (i.e., pathergy) [26]. Akatsuka et al. suggested the presence of monoclonal gammopathy (MG) as the possible cause of PG-associated CKD, in which MG leads to a rapidly progressive renal failure [3]. Others propose a mechanism that might include an underlying vascular insufficiency, especially in patients with ulcerative PG in the lower extremities [11]. The most common locations for PG found in these patients include the lower extremities, skin overlying an arteriovenous fistula, and previous surgery sites $[3,11,26$, 53]. Furthermore, ulcerative, vegetative, and atypical PG have been reported in this patient population $[3,11,21,26$, 53]. Even though CKD is a risk factor for wound healing

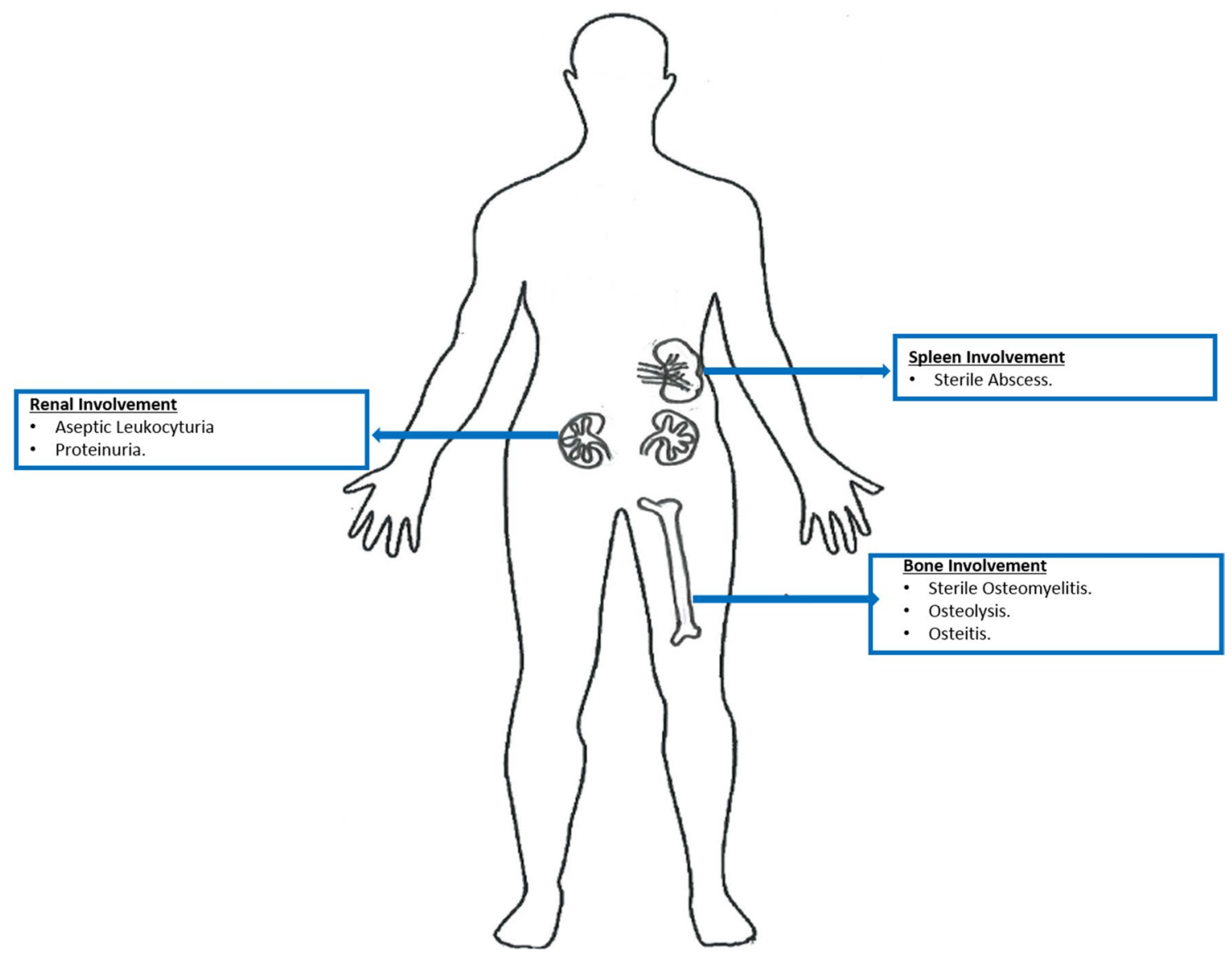

Fig. 2 Less common extracutaneous involvement in pyoderma gangrenosum 
impairment, these lesions respond well to either topical or systemic corticosteroid therapy as well as topical or intralesional steroids in conjunction with gradual improvement of the renal function.

\section{PG and bone involvement}

Bone involvement of PG is also rare, with only few case reports in literature. Sterile osteomyelitis represents the main type of involvement in patients with extracutaneous PG compromising the bone [17, 18, 35, 52, 54, 58, 61] (Fig. 2). In seven case reports found in the literature, sterile osteomyelitis has been described in four patients $[17,18,54,58$, 61] whereas osteitis and osteolysis were described in two patients [35, 52]. High temperature, arthralgia, and myalgia are usually the general symptoms present in these patients. The onset of bone involvement may be preceded $[35,54$, $58,61]$ or followed $[17,18,52]$ by the diagnosis of PG. Five out of these seven patients with bone involvement were pediatric, ranging from 9 months to 10 years of age, and the remaining two patients were older adults in their $70 \mathrm{~s}$. Bone biopsy in these cases showed acute or chronic inflammatory infiltrates (i.e., multinucleated giant cells, pigmented plasma cells, histiocytes, and lymphoid aggregates), resorption of bone trabeculae, and fibrosis. Though bone involvement may manifest as osteolysis of underlying bone, cultures from bone and blood were negative [52]. All patients were treated with corticosteroids that improved both cutaneous and skeletal findings.

\section{PG and spleen involvement}

Splenic involvement in PG is extremely rare but can affect any age, including a few pediatric cases under the age of 10 [7, 34] (Fig. 2). Lesions are often detected on imaging as abscesses, with tissue analysis revealing sterile, non-specific neutrophilic infiltrate. All cases of splenic PG were associated with cutaneous ulcers characteristic of PG, though the timing of these lesions may vary. Most often, splenic lesions are found preceded by characteristic skin lesions, especially in patients with known history of PG [20, 32, 44,

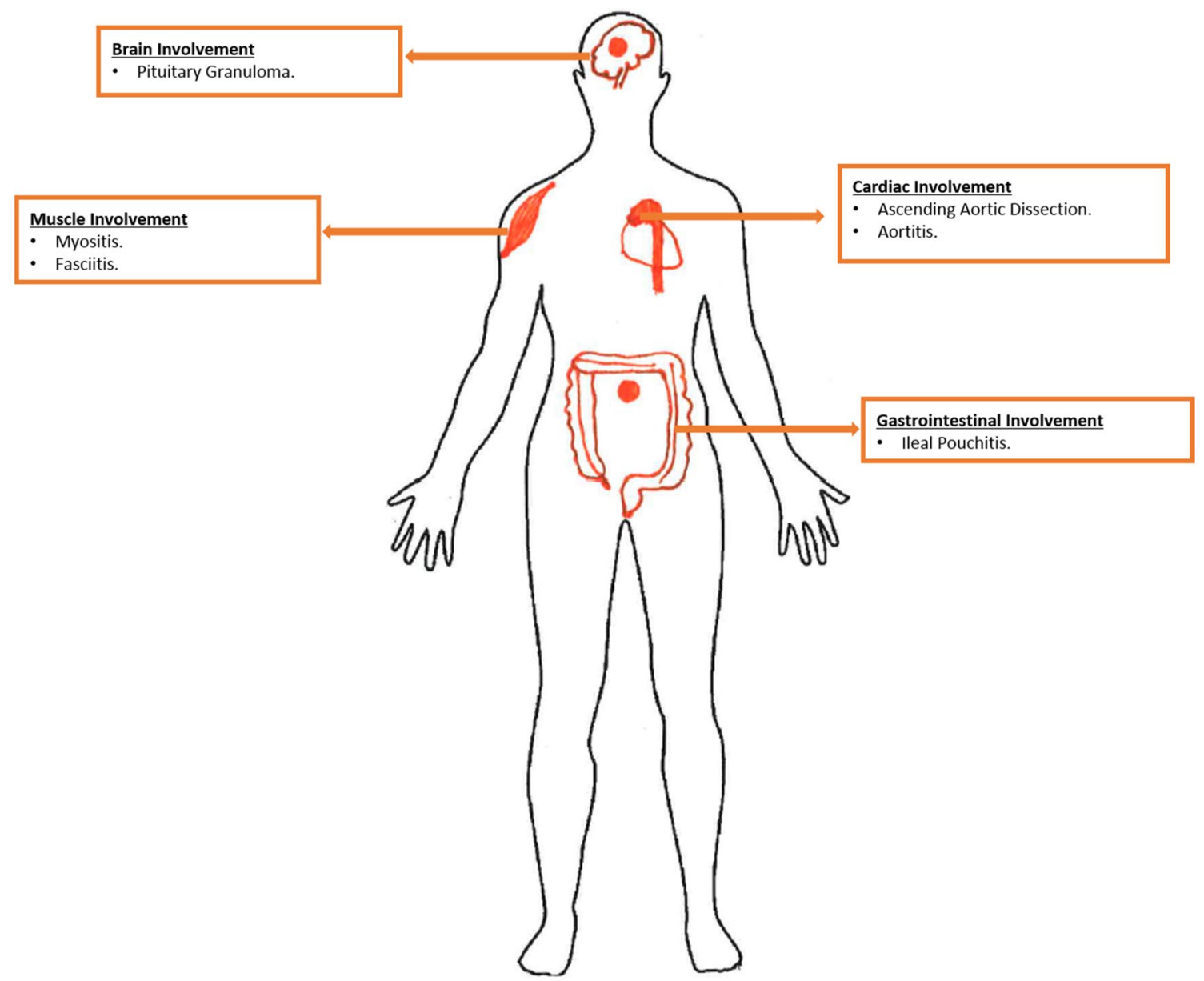

Fig. 3 Rare extracutaneous involvement in pyoderma gangrenosum. Brain, muscle, heart, and gastrointestinal involvement are the least commonly reported in the literature 
45], although one case reported spleen involvement as the initial presenting symptom [61].

PG with splenic involvement can be associated with additional involvement of other organs including the liver [45], kidney [10], lung [7], and bone [61]. Though underlying hematologic disease has been associated with PG, its relationship with splenic involvement is unclear. One case was associated with known IgA gammopathy [44] and another reported elevation of total IgA [7]. Chronic monomyelocytic leukemia was reported in one patient [61].

Differential diagnoses for splenic lesions in PG include vasculitis, tumor, and infection. However, invasive procedures to rule out these entities are generally avoided due to concerns of pathergy. The treatment of PG with splenic involvement generally involves systemic immunosuppression, and refractory cases have reported some success using biologics such as infliximab or adalimumab [7, 32].
Most patients usually improve with systemic immunotherapy, though challenging cases can experience recurrences requiring increasing dose of systemic steroids or addition of systemic cyclosporine. One death was reported after recurrence of $\mathrm{PG}$ with splenic involvement, though the ultimate cause of death was attributed to generalized peritonitis due to bowel infarction of unknown etiology [15].

\section{Other extracutaneous involvement}

Other systemic extracutaneous involvements of PG have been reported sporadically and are even more rare (Fig. 3) which include joints [16, 43, 47], pituitary granuloma [12], aortitis [36], myositis [25, 37], and ileal pouchitis [1] (Table 2).

Table 2 Features of types of extracutaneous pyoderma gangrenosum

\begin{tabular}{|c|c|c|c|c|}
\hline Systemic involvement & Clinical manifestation & Laboratory findings & Histology & References \\
\hline Pulmonary & $\begin{array}{l}\text { High temperature } \\
\text { Variable pulmonary symp- } \\
\text { toms } \\
\text { It may present either before } \\
\text { or after skin ulceration }\end{array}$ & $\begin{array}{l}\text { Chest } x \text { ray: interstitial } \\
\text { infiltrates mediastinal or } \\
\text { hilar lymphadenopathy, and } \\
\text { consolidation. Cavitating or } \\
\text { non-cavitating lesions }\end{array}$ & $\begin{array}{l}\text { Neutrophil infiltration } \\
\text { Granulomatous inflammation }\end{array}$ & {$[22,28,38,55]$} \\
\hline Renal & $\begin{array}{l}\text { Pyuria, hematuria, and } \\
\text { oliguria } \\
\text { Most common locations of } \\
\text { skin ulceration include } \\
\text { lower extremities, skin } \\
\text { overlying an arteriovenous } \\
\text { fistula, and previous sur- } \\
\text { gery sites }\end{array}$ & $\begin{array}{l}\text { Aseptic leukocyturia and } \\
\text { proteinuria } \\
\text { High levels of creatinine and } \\
\text { BUN (depending on the } \\
\text { level of compromise) }\end{array}$ & $\begin{array}{l}\text { Dense granular and mononu- } \\
\text { clear infiltrate, xanthoma- } \\
\text { tous macrophages } \\
\text { Necrosis can also be found }\end{array}$ & [10] \\
\hline Ocular & $\begin{array}{l}\text { Periocular ulceration. Fistula } \\
\text { to the eyelids may also be } \\
\text { present } \\
\text { Extracutaneous (involving } \\
\text { the eye itself) } \\
\text { Most commonly unilateral } \\
\text { Ulcerative PG is the most } \\
\text { common type }\end{array}$ & Non-specific & $\begin{array}{l}\text { Neutrophil infiltration and/ } \\
\text { or acute inflammatory } \\
\text { infiltrate } \\
\text { Necrosis, dermal abscesses } \\
\text { Chronic inflammatory } \\
\text { infiltrate }\end{array}$ & {$[27,45,50]$} \\
\hline Spleen & $\begin{array}{l}\text { Abdominal pain } \\
\text { Splenic PG may occur before } \\
\text { or after skin lesions }\end{array}$ & $\begin{array}{l}\text { MRI: intra-splenic and sub- } \\
\text { diaphragmatic collection } \\
\text { CT and US: splenic abscess- } \\
\text { negative culture }\end{array}$ & Neutrophilic infiltration & {$[7,10,34,44]$} \\
\hline Bone & $\begin{array}{l}\text { High temperature } \\
\text { Arthralgia } \\
\text { Regional tenderness and } \\
\text { swelling } \\
\text { Myalgia } \\
\text { Bone involvement may occur } \\
\text { before, concurrently, or } \\
\text { after the skin lesions } \\
\text { Regional lymphadenopathy }\end{array}$ & $\begin{array}{l}\text { Bone scan: uptake findings } \\
\text { consistent with osteolysis } \\
\text { X ray: moth-eaten erosive } \\
\text { changes. Radiolucent lesion } \\
\text { with periosteal reaction } \\
\text { CT: Osteolysis }\end{array}$ & $\begin{array}{l}\text { Sterile osteomyelitis: chronic } \\
\text { inflammatory cells (i.e., } \\
\text { lymphocytes and histio- } \\
\text { cytes) } \\
\text { Fibrosis } \\
\text { Osteitis and osteolysis }\end{array}$ & {$[17,18,35,52,54,58,61]$} \\
\hline
\end{tabular}

Pulmonary and ocular extracutaneous manifestations of PG are the most common among these patients. Visceral involvement which includes renal, spleen, and bone involvement and among others have also been reported 


\section{Conclusion}

The association of PG with underlying inflammatory conditions is well known. However, extracutaneous systemic manifestations of PG are considered uncommon but still important in the management of these patients. Being aware of extracutaneous involvement of PG may provide clinical clues to improve diagnostic work up of challenging cases (e.g., PG vs GPA) as overlapping systemic manifestations of classically associated comorbidities can coexist. The use of systemic immunosuppressive therapy should be warranted in patients with PG and extracutaneous manifestations regardless of the severity of the cutaneous lesion. In PG patients, though the presence of extracutaneous manifestations apparently does not impact mortality, the impact on long-term morbidity remains unknown. That being said, it is necessary to establish multicenter collaboration and registries to address the limited knowledge we have of the natural course of this disease and its associated extracutaneous manifestations.

Authorship Every author listed meets the qualifications for authorship and has had the opportunity to read and comment upon the submitted manuscript.

Funding This article received no specific grant from any funding agency in the public, commercial, or not-for-profit sectors.

\section{Compliance with ethical standards}

Conflict of interest The authors of this article have no conflict of interest to declare.

Prior presentation The authors declare that this article has not been published previously.

\section{References}

1. Abdelrazeq AS, Lund JN, Leveson SH (2004) Pouchitis-associated pyoderma gangrenosum following restorative proctocolectomy for ulcerative colitis. Eur J Gastroenterol Hepatol 16(10):1057-1058

2. Ahronowitz I, Harp J, Shinkai K (2012) Etiology and management of pyoderma gangrenosum: a comprehensive review. Am J Clin Dermatol 13(3):191-211

3. Akatsuka T, Kawata T, Hashimoto S, Nakamura S, Koike T (1997) Rapidly progressive renal failure occurring in the course of pyoderma gangrenosum and IgA (lambda) monoclonal gammopathy. Intern Med 36(1):40-43

4. Al-Hwiesh AK (2006) Pyoderma gangrenosum in a renal transplant recipient: a case report. Saudi J Kidney Dis Transpl 17(4):559-563

5. Alavi A, French LE, Davis MD, Brassard A, Kirsner RS (2017) Pyoderma gangrenosum: an update on pathophysiology, diagnosis and treatment. Am J Clin Dermatol 18(3):355-372
6. Alimagham M, Amini-Afshar S, Farahmand S, Pour-Kazemi A, Pour-Reza-Gholi F, Masood S (2005) Frequency of infectious skin lesions in kidney transplant recipients. Urol J 2(4):193-196

7. Allen CP, Hull J, Wilkison N, Burge SM (2013) Pediatric pyoderma gangrenosum with splenic and pulmonary involvement. Pediatr Dermatol 30(4):497-499

8. Branagan NM, Higgins SP, Halim SA, Le TH (2009) Systemic polyarteritis nodosa mimicking pyoderma gangrenosum in a rare association with small lymphocytic leukaemia/chronic lymphocytic leukaemia. Clin Exp Dermatol 34(5):e127-e129

9. Cartier H, Plantin P, Leroy JP, Larzul JJ (1995) Pyoderma gangrenosum, subcorneal IgA pustulosis and recurrent neutrophilic pleural and pulmonary diseases in a patient with IgA gammopathy. Ann Dermatol Venereol 122(3):97-101

10. Carvalho LR, Zanuncio VV, Gontijo B (2013) Pyoderma gangrenosum with renal and splenic impairment-case report. An Bras Dermatol 88(6 Suppl 1):150-153

11. Castillo RF, Canadas-De la Fuente GA, Husein-Elahmed H, Cantero-Hinojosa J (2011) Pyoderma gangrenosum developing over an arteriovenous fistula scar. Intern Med J 41(5):436-437

12. Chanson P, Timsit J, Kujas M, Violante A, Guillausseau PJ, Derome PJ et al (1990) Pituitary granuloma and pyoderma gangrenosum. J Endocrinol Invest 13(8):677-681

13. Chokoeva AA, Cardoso JC, Wollina U, Tchernev G (2017) Pyoderma gangrenosum-a novel approach? Wien Med Wochenschr 167(3-4):58-65

14. Cordier JF, Valeyre D, Guillevin L, Loire R, Brechot JM (1990) Pulmonary Wegener's granulomatosis. A clinical and imaging study of 77 cases. Chest 97(4):906-912

15. Cosgarea R, Senila SC, Badea R, Ungureanu L (2016) Pyoderma gangrenosum with spleen involvement. Review of the literature and case report. J Dermatol Case Rep 10(2):26-31

16. Cugno M, Gualtierotti R, Meroni PL, Marzano AV (2018) inflammatory joint disorders and neutrophilic dermatoses: a comprehensive review. Clin Rev Allergy Immunol 54(2):269-281

17. Dagan O, Barak Y, Metzker A (1995) Pyoderma gangrenosum and sterile multifocal osteomyelitis preceding the appearance of Takayasu arteritis. Pediatr Dermatol 12(1):39-42

18. East-Innis A, Desnoes R, Thame K, Shirley S, Gilbert D (2005) Pyoderma gangrenosum associated with osteomyelitis in a paediatric patient: a case report. West Indian Med J 54(3):207-209

19. Fournie P, Malecaze F, Coullet J, Arne JL (2007) Pyoderma gangrenosum with necrotizing sclerokeratitis after cataract surgery. J Cataract Refract Surg 33(11):1987-1990

20. Fujikawa T, Suzuka T (2017) Rare case of pyoderma gangrenosum originating in the spleen. BMJ Case Rep 2017:pii:bcr2016216909

21. Fujita T, Kinukawa T, Hattori R, Suzuki A, Ishida S, Kimura T et al (2009) Successful renal transplantation for a patient with pyoderma gangrenosum. Transpl Proc 41(1):437-440

22. Gade M, Studstrup F, Andersen AK, Hilberg O, Fogh C, Bendstrup E (2015) Pulmonary manifestations of pyoderma gangrenosum: 2 cases and a review of the literature. Respir Med 109(4):443-450

23. Gameiro A, Pereira N, Cardoso JC, Goncalo M (2015) Pyoderma gangrenosum: challenges and solutions. Clin Cosmet Investig Dermatol 8:285-293

24. Genovese G, Tavecchio S, Berti E, Rongioletti F, Marzano AV (2018) Pyoderma gangrenosum-like ulcerations in granulomatosis with polyangiitis: two cases and literature review. Rheumatol Int 38(6):1139-1151

25. Goldshmid O, Dovorish Z, Zehavi T, Eisen A, Bar-Dayan Y, Amital $\mathrm{H}$ (2011) Coexistent pyoderma gangrenosum and tibialis anterior myositis as presenting manifestations of Crohn's disease: case report and review of the literature. Rheumatol Int 31(4):525-527 
26. Goto M, Okamoto O, Fujiwara S, Yanagi T, Komada S, Yokoyama $S$ et al (2002) Vegetative pyoderma gangrenosum in chronic renal failure. Br J Dermatol 146(1):141-143

27. Gupta AS, Ortega-Loayza AG (2017) Ocular pyoderma gangrenosum: a systematic review. J Am Acad Dermatol 76(3):512-518

28. Gupta AS, Greiling TM, Ortega-Loayza AG (2018) A systematic review of pyoderma gangrenosum with pulmonary involvement: clinical presentation, diagnosis and management. J Eur Acad Dermatol Venereol 32(7):e295-e297

29. Hamzi AM, Bahadi A, Alayoud A, El Kabbaj D, Benyahia M (2013) Skin ulcerations in a lupus hemodialysis patient with hepatitis C infection: what is your diagnosis? Iran J Kidney Dis 7(3): 191

30. Harper SL, Letko E, Samson CM, Zafirakis P, Sangwan V, Nguyen Q et al (2001) Wegener's granulomatosis: the relationship between ocular and systemic disease. J Rheumatol 28(5):1025-1032

31. Hoffman GS, Kerr GS, Leavitt RY, Hallahan CW, Lebovics RS, Travis WD et al (1992) Wegener granulomatosis: an analysis of 158 patients. Ann Intern Med 116(6):488-498

32. Hubbard VG, Friedmann AC, Goldsmith P (2005) Systemic pyoderma gangrenosum responding to infliximab and adalimumab. Br J Dermatol 152(5):1059-1061

33. Jha PK, Rana A, Kapoor S, Kher V (2015) Pyoderma gangrenosum in a renal transplant recipient: a case report and review of literature. Indian J Nephrol 25(5):297-299

34. Johnson JL, West DA, Haggstrom AN (2015) Pyoderma gangrenosum associated with an aseptic splenic abscess in a patient with neurofibromatosis. Pediatr Dermatol 32(1):113-117

35. Kazmierczak-Kocwin A, Pieczyrak R, Kusz D, Kucharz E, Kusz M (2016) Osteitis in the course of pyodema gangrenosum. Case raport. Ortop Traumatol Rehabil 18(6):611-619

36. Linck V, Sanchez B, Baubion E, Molinie V, Deligny C, Quist $\mathrm{D}$ et al (2015) Pyoderma gangrenosum and neutrophilic aortitis preceding the development of rheumatoid arthritis. Ann Dermatol Venereol 142(6-7):425-429

37. Marie I, Levesque H, Joly P, Reumont G, Courville P, Baudrimont $\mathrm{M}$ et al (2001) Neutrophilic myositis as an extracutaneous manifestation of neutrophilic dermatosis. J Am Acad Dermatol 44(1):137-139

38. Maritsi DN, Tavernaraki K, Vartzelis G (2015) Pyoderma gangrenosum with systemic and pulmonary involvement in a toddler. Pediatr Int 57(3):505-506

39. Marzano AV, Ishak RS, Lazzari R, Polloni I, Vettoretti S, Crosti C (2012) Vulvar pyoderma gangrenosum with renal involvement. Eur J Dermatol 22(4):537-539

40. Marzano AV, Raimondo MG, Berti E, Meroni PL, Ingegnoli F (2017) Cutaneous manifestations of ANCA-associated small vessels vasculitis. Clin Rev Allergy Immunol 53(3):428-438

41. Marzano AV, Borghi A, Wallach D, Cugno M (2018) A comprehensive review of neutrophilic diseases. Clin Rev Allergy Immunol 54(1):114-130

42. Maverakis E, Ma C, Shinkai K, Fiorentino D, Callen JP, Wollina U et al (2018) Diagnostic criteria of ulcerative pyoderma gangrenosum: a delphi consensus of international experts. JAMA Dermatol 154(4):461-466

43. Meng X, Zhu X, Chen L, Wu J, Liu G, Xia B (2015) Pyoderma gangrenosum of articulations carpi associated with ulcerative colitis: one case report. Int J Clin Exp Med 8(10):19184-19187

44. Mijuskovic ZP, Zecevic RD, Pavlovic MD (2004) Pyoderma gangrenosum with spleen involvement and monoclonal IgA gammopathy. J Eur Acad Dermatol Venereol 18(6):697-699

45. Miserocchi E, Modorati G, Foster CS, Brancato R (2002) Ocular and extracutaneous involvement in pyoderma gangrenosum. Ophthalmology 109(10):1941-1943

46. Monari P, Moro R, Motolese A, Misciali C, Baraldi C, Fanti PA et al (2018) Epidemiology of pyoderma gangrenosum: results from an Italian prospective multicentre study. Int Wound J 15(6):875-879

47. Ochiai T, Hara H, Shimojima H, Fujitsuka A, Morishima T, Yamazaki $T$ et al (2002) Articular and pancreatic involvement in pyoderma gangrenosum associated with myelodysplastic syndrome. Dermatology 205(1):70-72

48. Patchefsky AS, Israel HL (1973) Pulmonary Wegener's granulomatosis. Ann Clin Lab Sci 3(4):249-258

49. Regnier-Rosencher E, Bizet N, Mery L (2011) Pyoderma gangrenosum associated with renal carcinoma. J Am Acad Dermatol 64(6):1208-1211

50. Rose GE, Barnes EA, Uddin JM (2003) Pyoderma gangrenosum of the ocular adnexa: a rare condition with characteristic clinical appearances. Ophthalmology 110(4):801-805

51. Sakata KK, Penupolu S, Colby TV, Gotway MB, Wesselius LJ (2016) Pulmonary pyoderma gangrenosum without cutaneous manifestations. Clin Respir J 10(4):508-511

52. Samlaska CP, Smith RA, Myers JB, Bottini AG, Person DA (1995) Pyoderma gangrenosum and cranial osteolysis: case report and review of the paediatric literature. Br J Dermatol 133(6):972-977

53. Sangiray H, Nguyen JC, Turiansky GW, Norwood C (2006) Pyoderma gangrenosum occurring near an arteriovenous dialysis shunt. Int J Dermatol 45(7):851-853

54. Schaen L, Sheth AP (1998) Skin ulcers associated with a tender and swollen arm: pyoderma gangrenosum (PG) in association with chronic recurrent multifocal osteomyelitis (CRMO). Arch Dermatol 134(9):1146-1147 (9-50)

55. Scherlinger M, Guillet S, Doutre MS, Beylot-Barry M, Pham-Ledard A (2017) Pyoderma gangrenosum with extensive pulmonary involvement. J Eur Acad Dermatol Venereol 31(4):e214-e216

56. Schlesinger IH, Farber GA (1995) Cutaneous ulceration resembling pyoderma gangrenosum in the primary antiphospholipid syndrome: a report of two additional cases and review of the literature. J La State Med Soc 147(8):357-361

57. Su LH, Chiu HC, Hsiao CH (2005) Multiple neutrophilic dermatoses occurring in a pediatric patient with glomerulonephritis. $\mathrm{J}$ Am Acad Dermatol 52(2 Suppl 1):28-30

58. Sundaram M, McDonald D, Engel E, Rotman M, Siegfried EC (1996) Chronic recurrent multifocal osteomyelitis: an evolving clinical and radiological spectrum. Skeletal Radiol 25(4):333-336

59. Tarabishy AB, Schulte M, Papaliodis GN, Hoffman GS (2010) Wegener's granulomatosis: clinical manifestations, differential diagnosis, and management of ocular and systemic disease. Surv Ophthalmol 55(5):429-444

60. Thickett DR, Richter AG, Nathani N, Perkins GD, Harper L (2006) Pulmonary manifestations of anti-neutrophil cytoplasmic antibody (ANCA)-positive vasculitis. Rheumatology (Oxford) 45(3):261-268

61. Vadillo M, Jucgla A, Podzamczer D, Rufi G, Domingo A (1999) Pyoderma gangrenosum with liver, spleen and bone involvement in a patient with chronic myelomonocytic leukaemia. Br J Dermatol 141(3):541-543

62. Wollina U (2015) Pyoderma gangrenosum-a systemic disease? Clin Dermatol 33(5):527-530

Publisher's Note Springer Nature remains neutral with regard to jurisdictional claims in published maps and institutional affiliations. 